\title{
An Anti-Inflammatory Adrenocorticalsteroid Hydrocortisonesodiumsuccinate, Hydrocortisone Preparation and Validated for the Confirmation/ Determination and Quantification of Hydrocortisone
}

\author{
Krishnasarma Pathy* \\ Head R\&D-QC/QA, IPL Research Centre Lucknow, India

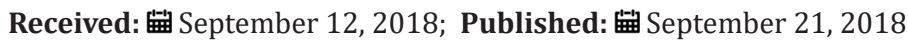 \\ *Corresponding author: Krishnasarma pathy, Head R\&D-QC/ QA, IPL Research Centre Lucknow, India
}

\section{Abstract}

Hydrocortisone is a naturally occurring corticosteroid hormone secreted by the adrenal cortex and released during times of stress. The synthetic drug is employed in the management of inflammatory and rheumatoid diseases, allergic conditions, and autoimmune disorders such as Addison's disease (adrenal insufficiency disease). Hydrocortisone is commercially available in pharmaceutical formulations such as tablets, capsules, creams, ointments, and injections. Hydrocortisone may exist commercially as the unchanged hormone or as the acetate, cypionate, sodium phosphate, butyrate, valerate, and the sodium succinate forms. Preparation of the present paper provides a method for preparation of hydrocortisone , method for preparation of hydrogenation cortisone sodium succinate reaction temperature is low, fast, easy to produce during the reaction of other impurities, fewer side effects and was concentrated, high yield, where water and other solvents content is low, to lay the foundation for post-drying, hydrogenation of the hydrocortisone sodium succinate prepared in line with CP2005 and USP28 standards, for clinical use and also an isocratic sensitive and precise reverse phase high-performance liquid chromatography (RP-HPLC) method was developed and validated for the determination and quantification of hydrocortisone in controlled-release and conventional (tablets and injections) pharmaceutical preparations. Chromatographic separation was achieved on an ODS (C18), 5m, $4.6 \times 150 \mathrm{~mm}$, with an isocratic elution using a freshly prepared mobile phase of composition methanol: water: acetic acid (60:30:10, v/v/v) at a flow rate of $1.0 \mathrm{ml} / \mathrm{min}$.

The detection of the drug was successfully achieved at a wavelength of $254 \mathrm{~nm}$. The retention time obtained for the drug was $2.26 \mathrm{~min}$. The proposed method produced linear detectable responses in the concentration range of 0.02 to $0.4 \mathrm{mg} / \mathrm{ml}$ of hydrocortisone. High recoveries of $98-101 \%$ were attained at concentration levels of $80 \%, 100 \%$, and $120 \%$. The intraday and interlay precision (RSD) were $0.19-0.55 \%$ and $0.33-0.71 \%$, respectively. A comparison of hydrocortisone analyses data from the developed method and the official USP method showed no significant difference 0 at a $95 \%$ confidence interval. The method was successfully applied to the determination and quantification of hydrocortisone in six controlled-release and fifteen conventional release pharmaceutical preparations.

\section{Introduction}

Hydrocortisone sodium succinate is an anti-inflammatory adrenocortical steroid. This highly water-soluble sodium succinate ester of hydrocortisone permits the immediate intravenous administration of high doses of hydrocortisone in a small volume of diluent and is particularly useful where high blood levels of hydrocortisone are required rapidly. A-Hydrocort sterile powder is available for intravenous or intramuscular administration. $100 \mathrm{mg}-$ Vials containing hydrocortisone sodium succinate equivalent to $100 \mathrm{mg}$ hydrocortisone, also $0.8 \mathrm{mg}$ monobasic sodium phosphate anhydrous, $8.73 \mathrm{mg}$ dibasic sodium phosphate anhydrous. When necessary, the $\mathrm{pH}$ was adjusted with sodium hydroxide so that the $\mathrm{pH}$ of the reconstituted solution is within the USP specified range of 7 to 8 (Figure 1). 


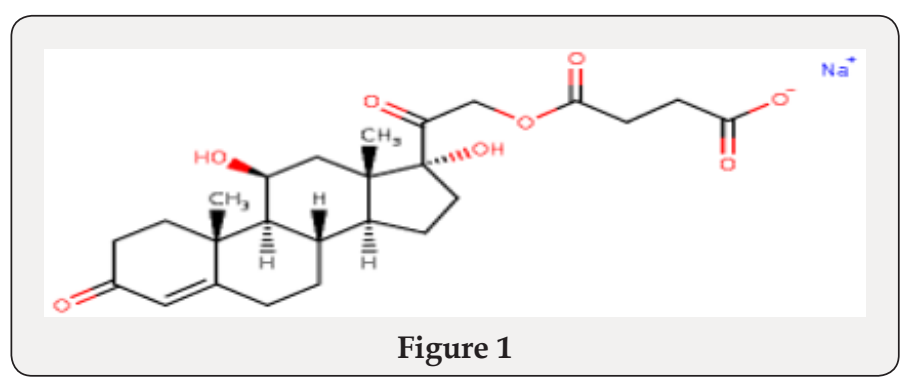

\section{Preparation of Solutions}

$100 \mathrm{mg}$ - For intravenous or intramuscular injection, prepare solution by aseptically adding not more than $2 \mathrm{~mL}$ of Bacteriostatic Water for Injection or Bacteriostatic Sodium Chloride Injection to the contents of one vial. Further dilution is not necessary for intravenous or intramuscular injection. For intravenous infusion, first prepare solution by adding not more than $2 \mathrm{~mL}$ of Bacteriostatic Water for Injection to the vial; this solution may then be added to 100 to $1000 \mathrm{~mL}$ of the following: $5 \%$ dextrose in water (or isotonic saline solution or $5 \%$ dextrose in isotonic saline solution if patient is not on sodium restriction). In cases where administration of a small volume of fluid is desirable, 100 $\mathrm{mg}$ of hydrocortisone sodium succinate may be added to $50 \mathrm{~mL}$ of the above diluents. The resulting solutions are stable for at least 4 hours and may be administered either directly or by IV piggyback. When reconstituted as directed, pH's of the solutions range from 7 to 8 and the tonicities are: $100 \mathrm{mg}$ vial, .36 osmolar (Isotonic saline $=.28$ osmolar.) For intravenous or intramuscular injection, vial should be reconstituted with Bacteriostatic Water for Injection or Bacteriostatic Sodium Chloride.

For intravenous infusion, vial should be reconstituted with Bacteriostatic Water for Injection. Hydrocortisone and hydrocortisone salts are known for use as anti-inflammatory agents. It is common to use these active substances in the treatment of asthma in particular, endocrine disorders, dermatological disorders and allergic conditions, and acute adrenal insufficiency. Hydrocortisone and its salts belong to the family of corticosteroids. Hydrocortisone and its salts are susceptible to oxidation. Therefore, pharmaceutical solutions of these active ingredients always include at least one antioxidant. However, antioxidants used in these pharmaceutical solutions are themselves unstable. Therefore, it is known that these pharmaceutical solutions comprise a $2^{\text {nd }}$ antioxidant is disodium ethylenediamine tetraacetate (hereinafter abbreviated as "disodium EDTA"). The disodium EDTA serves to stabilize (or otherwise preserve) the antioxidant which is itself chosen to keep the hydrocortisone thus preserving oxidation.

\section{Preparation of Hydrocortisone}

Hydrocortisone Step A : 3 - [(1,2-ethanediyl) mercaptole] cyclic Androst-4-ene-3,11,17-trione.

a) Androst-4-ene-3,11,17-trione: Was mixed under inert gas at room temperature $1.05 \mathrm{~g}$ of 9alpha-bromo 11beta-hydroxy androst-4-ene-3,17-dione, $7.5 \mathrm{~cm}^{3}$ of ethyl acetate and $2.5 \mathrm{cc}$ of ethylene glycol. Refluxed under stirring for 10 hours, cooled and then added $10 \mathrm{~cm}^{3}$ of $2 \mathrm{~N}$ hydrochloric acid and $10 \mathrm{~cm}^{3}$ of water acid, stirred for 20 hours then remove the ethyl acetate under reduced pressure. After salting out with sodium chloride is cooled to $0^{\circ} \mathrm{C}$, the crystals were separated, washed with water and dried. Were repeated with methylene chloride, add ethyl acetate, methylene chloride is evaporated, ice the solution and the crystals were separated and dried. $0.52 \mathrm{~g}$ of the expected product, $\mathrm{mp}=221^{\circ} \mathrm{C}$. By extraction of the aqueous phase with methylene chloride and chromatography on silica of the crude product, eluting with mixture of ethyl chloride méthylèneacétate (95-5) is obtained, after crystallization from ethyl acetate, $0.097 \mathrm{~g}$ of expected product melting at $220^{\circ} \mathrm{C}$.

b) 3 - [(1,2-ethanediyl) mercaptole] cyclic androst-4ene-3,11,17-trione: Is room temperature under an inert gas mixture $100 \mathrm{~cm}^{3}$ of methanol, $5 \mathrm{~g}$ of product obtained as described above, $1.8 \mathrm{~cm}^{3}$ of ethanedithiol and $2.5 \mathrm{~cm}^{3}$ boron trifluoride etherate. After $1 \mathrm{~h} 30$ with stirring the methanol is evaporated, taken up in methylene chloride, washed with saturated aqueous sodium bicarbonate, water and dried and evaporated to dryness. The product was crystallized obtained in hexane and obtained $5.99 \mathrm{~g}$ of expected product melting at $160^{\circ} \mathrm{C}$.

NMR Spectrum $\left(\mathrm{CDCl}_{3} 90 \mathrm{MHZ} \mathrm{ppm}\right)$

18- $\mathrm{CH}_{3}: 0.85 ; 19--\mathrm{CH}_{3}: 1.27$; thioketal: 3.17 to $3.47 ; \mathrm{H}_{4}: 5.6$

IR Spectrum $\left(\mathrm{CHCl}_{3}\right)$

Absence of $\Delta^{4}$ 3-one; absorptions at $1645 \mathrm{~cm}^{-1}(\mathrm{C}=\mathrm{C}), 1709 \mathrm{~cm}$ ${ }^{1}$ ( $\mathrm{C}=0$ in 11-position), $1740 \mathrm{~cm}^{-1}$ ( $\mathrm{C}=0$ in 17 -position).

A. Step A: 3-[(1,2-ethanediyl) mercaptole] cyclic Androst4-ene-3,11,17-trione under inert gas mixture $4 \mathrm{~g}$ of 9 alpha-bromo 11beta-hydroxy androst-4-ene-3,20-dione and $40 \mathrm{~cm}^{3}$ of ethyl acetate and then added at ambient temperature $0.9 \mathrm{~cm}^{3}$ of ethane dithiol. then slowly added $0.09 \mathrm{~cm}^{3}$ of hydrochloric acid at $22^{\circ}$ Bé then stirred for 6 hours. Is then introduced $9.3 \mathrm{cc}$ of ethylene glycol was refluxed for 20 hours and then cooled to $20^{\circ} \mathrm{C}$ and pour the reaction mixture into a mixture of $40 \mathrm{~cm}^{3}$ of $2 \mathrm{~N}$ hydrochloric acid and $40 \mathrm{~cm}^{3}$ of water. stirred for 16 hours then removed ethyl acetate under reduced pressure $(20 \mathrm{~mm} / \mathrm{Hg})$ at $35^{\circ} \mathrm{C}$ maximum then the suspension is cooled to $0,+5^{\circ} \mathrm{C}$, stirred for 1 hour and the crystals were separated. Washed with water and then dried and chromatographed on silica eluting with hexane-dioxane mixture (9-1). Is obtained $3.2 \mathrm{~g}$ of the expected product.

NMR Spectrum ( $\left.\mathrm{CDCl}_{3} 300 \mathrm{MHz} \mathrm{ppm}\right)$ : 18-- $\mathrm{CH}_{3}: 0.84$ (s); 19-$\mathrm{CH}_{3}: 1.26$ (s); thioketal: 3.15 to $3.4 ; \mathrm{H}_{4}: 5.57$; skeleton: 1.1 to $2.61(\mathrm{~m})$

IR Spectrum $\left(\mathrm{CHCl}_{3}\right)$ : Absorptions at $1741-1709 \mathrm{~cm}^{-1}$ (ketones); $1641 \mathrm{~cm}^{-1}(\mathrm{C}=\mathrm{C})$ 
B. Step B: Methyl 20-chloro-3,3,1,2-ethanediyl-bis(thio) !- $\Delta^{4}, 17(20)=$ pregnadien-11-one-21-oate 20-chloro-3,3-[1,2ethanediyl bis (thio)]-11-oxo-pregna-4,17(20)-dien methyl-21oate under an inert atmosphere is mixed $100 \mathrm{~cm}^{3}$ of tetrahydrofuran and $12.55 \mathrm{~g}$ of zinc powder. was slowly added at $-10^{\circ} /-15^{\circ} \mathrm{C}$, $7.9 \mathrm{~cm}^{3}$ of titanium tetrachloride and then a mixture of $100 \mathrm{~cm}^{3}$ of tetrahydrofuran, $8.6 \mathrm{~cm}^{3}$ of methyl trichloroacetate and $18 \mathrm{~g}$ of product obtained as described in Step A or A : The temperature was allowed to rise and then kept stirring at room temperature for $1 \mathrm{~h} 30 \mathrm{~min}$ then added at $+10 /+5^{\circ} \mathrm{C}, 100 \mathrm{~cm}^{3}$ of water-pyridine $(4-$ $1)$, stirred for 1 hour while allowing the temperature to rise then added $100 \mathrm{~cm}^{3}$ of concentrated hydrochloric acid-water mixture (6-4). Stirred for 15 minutes, extracted with methylene chloride, the organic phase washed with water, dried and the solvent evaporated. The crystals were dissolved in methylene chloride, added isopropyl ether, evaporating the methylene chloride, cooled and the crystals were separated. The mother liquors were chromatographed on silica eluting with cyclohexane-ethyl acetate mixture (8-2). Is recovered in total $21.8 \mathrm{~g}$ of expected product $\mathrm{F} \approx 175^{\circ} \mathrm{C}$.

\section{a) IR Spectrum $\left(\mathrm{CHCl}_{3}\right)$}

Absorptions at $1715 \mathrm{~cm}^{-1}$ and $1730 \mathrm{~cm}^{-1}(\mathrm{C}=0)$ max. 1705 $\mathrm{cm}^{-1} 1643 \mathrm{~cm}^{-1}$ (C=C $\Delta^{4}$ ) and $1610 \mathrm{~cm}^{-1}$ (C=C) NMR Spectrum $\left(\mathrm{CDCl}_{3} 90 \mathrm{MHz} \mathrm{ppm}\right)$ Mixture of isomers $20 \mathrm{Cl}$ 18-- $\mathrm{CH}_{3}: 1.02-0.98$; 19-- $\mathrm{CH}_{3}: 1.25$; thioketal: $3.33 ; \mathrm{CH}_{3}$--ester: 3.83-3.82; $\mathrm{H}_{4}$ : 5.58 .

C. Step C: 20-phenoxy-3,3-[1,2-ethanediyl bis (thio)]11-oxopregna-4,17 (20) -dien methyl-21-oate. Mixture is brought to reflux under an inert atmosphere a mixture of $18 \mathrm{~g}$ of phenol, $150 \mathrm{~cm}^{3}$ of butanone, $30 \mathrm{~g}$ of product obtained according to the procedure described in Step B, and $17.7 \mathrm{~g}$ of potassium carbonate. After 16 hours the mixture was poured into a mixture of $100 \mathrm{~cm}^{3}$ of water, $90 \mathrm{~g}$ ice and $10 \mathrm{~cm}^{3}$ of $10 \mathrm{~N}$ sodium hydroxide. Extracted with methylene chloride, the organic phase washed with water and concentrated. Is taken up with methanol, allowed to cool slowly and the crystals were separated and dried. into two streams are obtained $27.4 \mathrm{~g}$ of the expected product $\mathrm{F} \approx 208-210{ }^{\circ} \mathrm{C}$.

a) IR Spectrum ( $\left.\mathbf{C H C l}_{3}\right)$ : Absorption at 1592-1491 $\mathrm{cm}^{-1}$ (Aromatic $\mathrm{C}_{6} \mathrm{H}_{5}$-0-type); 1714-1705 $\mathrm{cm}^{-1} \quad(\mathrm{C}=0) ; 1646$ $\mathrm{cm}^{-1}(\mathrm{C}=\mathrm{C})$ NMR Spectrum $\left(\mathrm{CDCl}_{3} 90 \mathrm{MHz} \mathrm{ppm}\right)$

18- $\mathrm{CH}_{3}: 0.9 ; 19-\mathrm{CH}_{3}: 1.21$; thioketal: $3.33 ; \mathrm{CH}_{3}$ ester: $3.63 ; \mathrm{H}_{4}$ : 5.58; $\mathrm{C}_{6} \mathrm{H}_{5}: 6.81$ to 7.39 Mixture of isomers $20-0-\mathrm{C}_{6} \mathrm{H}_{5}$

D. Step D: (11beta) 3,3 - [(1,2-ethanediyl) mercaptole] cyclic 20-phenoxy-11,21-dihydroxy-pregna-4,17 (20) -dien-3-one. Is under an inert gas mixture $20 \mathrm{~g}$ of product obtained in Stage $\mathrm{C}$ and $200 \mathrm{~cm}^{3}$ of toluene, cooled to $-25{ }^{\circ} \mathrm{C}$ and slowly added $110 \mathrm{~cm}^{3}$ of a $20 \%$ solution of diisobutyl aluminum hydride in toluene. The temperature was allowed to rise to $+10{ }^{\circ} \mathrm{C}$, stirred for 1 hour then cooled again to $-15^{\circ} \mathrm{C}$ was slowly added $10 \mathrm{~cm}^{3}$ of methanol, allowed to rise to $0{ }^{\circ} \mathrm{C}$ and slowly added $200 \mathrm{cc}$ of $2 \mathrm{~N}$ hydrochloric acid. After decanting, the organic phase washed with water, dried and the solvent evaporated. The residue was chromatographed on silica eluting with toluene-ethyl acetate mixture (9-1). One obtains $17.4 \mathrm{~g}$ of expected product.

\section{a) IR Spectrum $\left(\mathrm{CHCl}_{3}\right)$ :}

Absorption at $1490-1596 \mathrm{~cm}^{-1}\left(\mathrm{C}_{6} \mathrm{H}_{5}-0-\mathrm{C}\right) ; 1644 \mathrm{~cm}^{-1}(\mathrm{C}=\mathrm{C})$ $\left.\Delta^{4}\right)$ and $1682 \mathrm{~cm}^{-1}(\mathrm{C}=\mathrm{C}) ; 3612 \mathrm{~cm}^{-1}$ (free $\mathrm{OH}$ ) NMR Spectrum $\left(\mathrm{CDCl}_{3}-\mathrm{C}_{5} \mathrm{D}_{5} \mathrm{~N}\right)(90 \mathrm{MHz} \mathrm{ppm})$

E. Step E: (11beta) 11,21-dihydroxy 20-phenoxypregna-4,17 (20) dien-3-one.Is dissolved $5 \mathrm{~g}$ of the product obtained above in $10 \mathrm{~cm}^{3}$ of methylene chloride and $30 \mathrm{~cm}^{3}$ of methanol, $2.5 \mathrm{~cm}^{3}$ of deionized water and $0.3 \mathrm{~g}$ of iodine. There is obtained a $\mathrm{pH}$ of 1.5 and is introduced in 15 minutes $1.4 \mathrm{cc}$ of hydrogen peroxide at $50 \%$. Neutralized oxidizing power by addition of $2 \mathrm{~g}$ of sodium thiosulphate. Then $5 \mathrm{~g}$ of clarcel, filtered and concentrated to dryness under reduced pressure. The dry extract is dissolved in methylene chloride, washed with a solution of $1 \mathrm{~g}$ sodium thiosulfate in $25 \mathrm{~cm}^{3}$ of water, decanted, dried and concentrated to dryness under reduced pressure to obtain $4.8 \mathrm{~g}$ of the expected crude product $1.8 \mathrm{~g}$ of purified product by chromatography on silica (eluent methylene chloride-isopropanol (97.5-2.5)) to obtain $1.7 \mathrm{~g}$ of desired product. $\mathrm{F}=188^{\circ} \mathrm{C}$.

\section{a) IR Spectrum $\left(\mathrm{CHCl}_{3}\right)$ :}

Absorptions at $3613 \mathrm{~cm}^{-1}(\mathrm{OH}) ; 1662,1617$ and $868 \mathrm{~cm}^{-1}\left(\Delta^{4}-3\right.$ oxo); $1597-1491 \mathrm{~cm}^{-1}\left(--0--\mathrm{C}_{6} \mathrm{H}_{5}\right)$

NMR Spectrum $\left(\mathrm{CDCl}_{3}-\mathrm{C}_{5} \mathrm{D}_{5} \mathrm{~N}--90 \mathrm{MHz} \mathrm{ppm}\right)$

$18-\mathrm{CH}_{3}: 1.17 ; 19--\mathrm{CH}_{3} \mathrm{Z}: 1.42 ; \mathrm{H}_{11}: 4.27 ; \mathrm{H}_{4}: 5.67 ; \mathrm{CH}_{2} \mathrm{OH}: 4.11$; $\mathrm{C}_{6} \mathrm{H}_{5}: 6.87$ to 7.37

F. Step F: (11beta) 11,21-dihydroxy 17,20-epoxy 20-phenoxy-pregna-4-en-3-one.under an inert gas are mixed $1.0 \mathrm{~g}$ of product obtained in Stage E, $10 \mathrm{~cm}^{3}$ of ethyl acetate and $5 \mathrm{~cm}^{3}$ of water are added. there is added $0.5 \mathrm{~g}$ of disodium phosphate, 0.65 $\mathrm{g}$ of perphthalic acid and $0.75 \mathrm{cc}$ of $50 \%$ hydrogen peroxide, stirred for 3 hours 15 minutes, add $0.15 \mathrm{~g}$ of disodium phosphate and 0, 20 $\mathrm{g}$ of perphthalic acid and stirred for 1 hour 15 minutes. then added $20 \mathrm{~cm}^{3}$ of ethyl acetate and $9 \mathrm{cc}$ of $1 \mathrm{~N}$ sodium hydroxide, stirred 5 minutes, decanting, washing the organic phase with water and water containing sodium bisulfite and sulfuric acid $1 \mathrm{~N}$, dried and evaporated to dryness. Was obtained $1.05 \mathrm{~g}$ of expected crude and unstable product was used as is for the following stage. Rf: 0.28 (silica-- $\mathrm{CH}_{2} \mathrm{Cl}_{2}$ /Dioxane--90/10).

\section{IR Spectrum $\left(\mathrm{CHCl}_{3}\right)$}

Absorption at $3613 \mathrm{~cm}^{-1}(\mathrm{OH}) ; 1662$ and $1616 \mathrm{~cm}^{-1}$ ( $\Delta^{4}$-3-one); 1600,1590 and $1494 \mathrm{~cm}^{-1}$ (aromatic) 
NMR Spectrum ( $\left.\mathrm{CDCl}_{3} 300 \mathrm{MHz} \mathrm{ppm}\right)$

$18--\mathrm{CH}_{3}: 1.29$ (s); 19-- $\mathrm{CH}_{3}: 1.43$ (s); --C-- $\mathrm{CH}_{2}$--0--: 3.49 (dd) and $4.20(\mathrm{dd}) ; \mathrm{H}_{11}$ eq.: $4.32 ; \mathrm{H}_{4}: 5.68 ; \mathrm{H}$ of $0-\mathrm{C}_{6} \mathrm{H}_{5}$ : para $7.06(\mathrm{t})$, ortho $7.13(\mathrm{~d})$ and meta $7.29(\mathrm{t})$.

G. STEP G: Hydrocortisone $5 \mathrm{ml}$ of methanol, $3 \mathrm{ml}$ of water and $0.08 \mathrm{ml}$ of $1 \mathrm{~N}$ sulfuric acid ( $\mathrm{pH} 2)$ were mixed together under an inert gas atmosphere and after $0.525 \mathrm{~g}$ of the product of Step F were added at ambient temperature, the mixture was stirred for 16 hours. The mixture was neutralized by the addition of sodium bicarbonate and extraction was carried out with methylene chloride. The organic phase was dried and evaporated to dryness. The residue was taken up in hot methylene chloride with $5 \%$ methanol, then concentrated until the start of crystallization. After cooling, the crystals were separated and dried. The mother liquors were concentrated, and the residue was chromatographed on silica eluting with a methylene chloride--methanol (95-5) mixture to obtain in total $0.318 \mathrm{~g}$ of the expected hydrocortisone melting at $224^{\circ} \mathrm{C}$. and having a specific rotation of $\alpha !^{20}{ }_{\mathrm{D}}=+164^{\circ} \pm 2^{\circ} 5(\mathrm{C}=1 \%$ in ethanol).

\section{a) IR Spectrum (nujol):}

Absorption at $3430 \mathrm{~cm}^{-1}(\mathrm{OH}), 1710 \mathrm{~cm}^{-1}(\mathrm{C}=0), 1642,1630$ and $1610 \mathrm{~cm}^{-1}$ ( $\Delta^{4}$-3-one).

\section{Hydrocortisone Hemisuccinate}

Preparation: A mixture of1 $\mathrm{Kg}$ hydrocortisone, $1.9 \mathrm{~kg}$ dimethyl formamide into a reaction tank dried ' and stirred at $20-25^{\prime} \mathrm{C}$ stirred solution clear. Slowly cooling to $10^{\circ} \mathrm{C}$, put $0.22 \mathrm{Kg}$ triethylamine was slowly added $0.8 \mathrm{Kg}$ succinic anhydride, control temperature of 15 $\mathrm{C}$ reaction maintain 3,5 hours. In the mixing state has been lowered to 2 diluted. $\mathrm{C}>\mathrm{s} 15 \mathrm{Kg}$ purified water, $5-8^{\circ} \mathrm{C}$ stand for 3 hours, filtered the material, color is white or off-white powder. The yield was $92.64 \%$, a melting point of $170{ }^{\circ} \mathrm{C}$

Example 2: Hydrocortisone sodium succinate Synthesis: (TC, completely dissolved with stirring for about 50min the method of Example 1 to give hydrocortisone succinate $50 \mathrm{~g}$, the ratio of the amount of $200 \mathrm{ml}$ of purified water was added, dissolution temperature Ol plus carbonate. sodium $9 \mathrm{~g}$, slowly add the ratio of the amount of acetone $100 \mathrm{ml}$, about $2 \mathrm{ml} /$ minute rate dropped, after the addition was complete, the temperature control at Ol (TC, thermal reaction $2 \mathrm{~h}$, gradually dissolving clear, plus carbon $2.5 \mathrm{~g}$, bleaching $30 \mathrm{~min}$, filter bucket filtered, concentrated under reduced pressure, T "3 (TC, vacuum should" $-0.08 \mathrm{MPa}$, hydrocortisone sodium succinate and concentrated to $46.32 \mathrm{~g}$, color is white or offwhite powder. The yield was $92.64 \%$, a melting point of $170{ }^{\circ} \mathrm{C}$.

Example 3: Hydrocortisone sodium succinate Synthesis: Example 1 obtained hydrocortisone succinate $50 \mathrm{~g}$, the ratio of the amount of added $165 \mathrm{ml}$ of purified water dissolution temperature of $10-20^{\circ} \mathrm{C}$, stirred for about $40 \mathrm{~min}$ completely dissolved. Sodium hydroxide $4.3 \mathrm{~g}$, slowly increase the ratio of the amount of acetone $100 \mathrm{ml}$, about $2 \mathrm{ml} /$ minute rate dropped, after the addition was complete, the temperature control at $10-20{ }^{\circ} \mathrm{C}$, the reaction was kept $1.5 \mathrm{~h}$, gradually dissolving clear added carbon $2.5 \mathrm{~g}$, bleaching $30 \mathrm{~min}$, filter bucket filtered, concentrated under reduced pressure, T "3 (TC, vacuum should" -0.08MPa, hydrocortisone sodium succinate and concentrated to $45.86 \mathrm{~g}$, color is white or off-white powder. The yield $91.72 \%$, m.p. $170^{\circ} \mathrm{C}$.

\section{Example 4}

Hydrocortisone sodium succinate Synthesis:

a) Example 1 obtained hydrocortisone succinate $50 \mathrm{~g}$, the ratio of the amount of $165 \mathrm{ml}$ of purified water was added, the reaction temperature is $10-20{ }^{\circ} \mathrm{C}$, stirred for about $40 \mathrm{~min}$ completely dissolved.Plus sodium bicarbonate $9 \mathrm{~g}$, slowly add acetone $100 \mathrm{ml}$, about $2 \mathrm{ml}$ / minute dropped, after the addition was complete, the temperature control at $10-20^{\circ} \mathrm{C}$, the reaction was kept $1.5 \mathrm{~h}$, gradually dissolving clear, plus carbon $2.5 \mathrm{~g}$, bleaching $30 \mathrm{~min}$, filter bucket filtered, concentrated under reduced pressure, $\mathrm{T}$ " 30 ' $\mathrm{C}$, vacuum should" $-0.08 \mathrm{MPa}$, hydrocortisone sodium succinate and concentrated to $47.25 \mathrm{~g}$, color is white or off-white powder. The yield was $94.5 \%, \mathrm{mp} 170.5^{\circ} \mathrm{C}$

Hydrocortisone sodium succinate Synthesis: Example 1 obtained hydrocortisone succinate $50 \mathrm{~g}$, the ratio of the amount of $165 \mathrm{ml}$ of purified water was added, the reaction temperature was 20-3 (TC, stirred for about 30min completely dissolved. plus sodium bicarbonate $9 \mathrm{~g}$, slowly add the ratio of the amount of acetone $100 \mathrm{ml}$, temperature and reaction $\mathrm{lh}$, gradually dissolving clear added carbon $2.5 \mathrm{~g}$, bleaching $30 \mathrm{~min}$, filter bucket filtered, concentrated under reduced pressure, T "3 (TC, vacuum should" $-0.08 \mathrm{MPa}$, hydrocortisone sodium succinate and concentrated to $47.4 \mathrm{~g}$, the color is white or off-white powder. The yield was $94.8 \%$, a melting point of $171^{\circ} \mathrm{C}$.

Hydrocortisone sodium succinate synthesis: by the method of Example 1 to give hydrocortisone Pine succinate 50g, 165ml of purified water was added, the reaction temperature is 30-40 ${ }^{\circ} \mathrm{C}$, stirred for about $20 \mathrm{~min}$ completely dissolved. Plus sodium bicarbonate $9 \mathrm{~g}$, slowly add the ratio of the amount of acetone $100 \mathrm{ml}$, about $2 \mathrm{ml} /$ minute rate dropped, after the addition was complete, the temperature control at $10-15{ }^{\circ} \mathrm{C}$, the reaction was kept $\mathrm{lh}$, gradually dissolving clear added carbon $2.5 \mathrm{~g}$, bleaching $30 \mathrm{~min}$, filter bucket filtered, concentrated under reduced pressure, $\mathrm{T}$ "30. C, the vacuum should «-0.08MPa, hydrocortisone sodium succinate and concentrated to $44.71 \mathrm{~g}$, color is white or off-white powder. The yield was $89.42 \%$, the melting point of 17 (TC).

b) Example 3: Hydrocortisone sodium succinate synthesis: by the method of Example 1 to give hydrocortisone Pine succinate $50 \mathrm{~g}, 165 \mathrm{ml}$ of purified water was added, the reaction temperature was 40-5 (TC, dissolved 20min. Add sodium bicarbonate 9g, slowly 
add acetone $100 \mathrm{ml}$, approximately $2 \mathrm{ml}$ / min speed of the dropwise addition, 'After the addition was complete, Temperature control in $10-15^{\prime} \mathrm{C}$, heat the reaction $1.5 \mathrm{~h}$, gradually dissolving clear, plus carbon $2.5 \mathrm{~g}$, bleaching $30 \mathrm{~min}$, filter bucket filtered, concentrated under reduced pressure, T "3 (TC, vacuum should" -0.08MPa, concentrated to hydrocortisone sodium succinate $46.32 \S$, the color is white or off-white powder. The yield was $92.64 \%$, the melting point of 170.5 .C. yield $93 \%, \mathrm{mp} 171^{\circ} \mathrm{C}$.

After a detailed description of the preferred embodiments, those skilled in the art can clearly understand, 'without departing from the scope and spirit of the above-mentioned patent applications under various changes and modifications, all based on technical essence of the invention of the above embodiments Any changes made simple equivalent change and modifications are within the scope of the present invention, the technical solution. And the present invention is also not limited to the examples cited in the specification embodiments.

A search of the literature revealed that few analytical methods such as ultraviolet spectrophotometry [2], electrokinetic capillary chromatography $[3,4]$, photochemically enhanced fluorescence [5], thin-layer chromatography- (TLC-) densitometry [1,6], and high-performance thin-layer chromatography (HPTLC) [7] have been used for the estimation of hydrocortisone in pharmaceutical formulations. However, modern chromatographic techniques suchas high-performance liquid chromatography (HPLC) [8-12] and ultraperformance liquid chromatography (UPLC) [13] are preferentially employed for the determination of hydrocortisone in conventional pharmaceutical products such as tablets, creams, and injections. The different HPLC methods employ different chromatographic conditions including the use of complex and sometimes expensive solvent systems. Thus, access to some of these solvent systems in resource-poor countries in the developing countries can be challenging. The development of a simple and economical HPLC method using readily available reagents for the identification and quantification of hydrocortisone in pharmaceutical preparations would be an advantage in resource-poor countries.

The upsurge of autoimmune diseases such as adrenal insufficiency is a major health concern and the long-term use of conventional hydrocortisone tablets in the management of such a condition is problematic. The twice or thrice daily dosing of conventional hydrocortisone tablets to patients with adrenal insufficiency disease is incapable of mimicking the unique diurnal cortisol circadian pattern. Thus, most persons with adrenal insufficiency continue to suffer from poor therapeutic management resulting in poor quality of life and increased mortality. There is therefore the need for the development of creative and innovative treatment models for hydrocortisone replacement therapy in such dire situations. The use of controlled-release hydrocortisone oral dosage forms holds great promise with the capability to replicate the unique physiological pattern of hydrocortisone. In addition, such formulations are better able to manage and control the levels of morning androgen levels. The accurate monitoring of the quality of these promising new drug therapies is an important prerequisite to obtain quality healthcare [14]. The improved therapy will enhance patient compliance and ensure the delivery of controlled amounts of hydrocortisone at the absorption site compared to the immediate release pattern of conventional tablets [15].

The aim of this study was to develop and validate a simple, sensitive, and reproducible isocratic reverse phase HPLC method with ultraviolet/visible (UV) detection capable of determination and quantification of hydrocortisone in conventional and controlled-release pharmaceutical preparations. The application of the method in determining the content of hydrocortisone in controlled-release and commercially available conventional dosage forms was also studied.

\section{Materials and Methods}

\section{Standards and Reagents}

The reference material of hydrocortisone (Sigma Aldrich, USA), HPLC grade methanol (Fisher Scientific, UK), glacial acetic acid (Fluka, Germany), and water (double distilled) were used. All stock and working solutions were freshly prepared with distilled water for HPLC analyses.

\section{Hydrocortisone Pharmaceutical Preparations}

Fifteen commercially available hydrocortisone pharmaceutical preparations, comprising nine tablet and six injectable formulations, were sampled from retail pharmacies within the Kumasi and Accra Metropolitan areas of Ghana. Additionally, four controlled-release hydrocortisone tablet formulations, two controlled-release capsule formulations, and one conventional release hydrocortisone tablet formulation were obtained from the Department of Pharmaceutics and Microbiology, University of Ghana School of Pharmacy, Accra, Ghana.

\section{Instrumentation and Optimized Chromatographic}

\section{Conditions}

A chromatograph comprising a P100 Spectra Series pump with a 785A Programmable Perkin Elmer UV/VIS absorbance detector was employed in the study. Isocratic mode of elution was employed. Chromatographic separation was successfully achieved on a JT Baker ${ }^{\circledR}$ ODS C18 column $(150 \times 4.60 \mathrm{~mm}$ ID, $5 \mu \mathrm{m}$ particle size $)$. Ultraviolet detection at a wavelength of $254 \mathrm{~nm}$ was able to ensure good resolution of peaks. The injection volume was $20 \mu \mathrm{L}$ and all analyses were undertaken at ambient temperature. A mobile phase consisting of methanol/water/acetic acid (60:30:10; v/v/v) at a flow rate of $1.00 \mathrm{ml} / \mathrm{min}$ was employed. All chromatographic data were acquired using PowerChrom series 280 integrator software. 


\section{Preparation of Standard Solution}

Fifty milligrams of hydrocortisone reference standard were accurately weighed and dissolved in $25 \mathrm{ml}$ of methanol as the diluent. The solution was transferred into a $50 \mathrm{ml}$ dry volumetric flask and was then sonicated for $5 \mathrm{~min}$. The volume was made up to the mark with methanol and mixed thoroughly ( $1 \mathrm{mg} / \mathrm{ml}$ stock solution). A one in ten ( 1 in 10) dilution was made to obtain a working solution with concentration of $0.10 \mathrm{mg} / \mathrm{ml}$ of hydrocortisone. This solution with the required working concentration was then injected to determine the retention time of the analyte of interest using the developed method.

\section{Analytical Method Validation}

The new HPLC method was validated in terms of linearity, limits of detection and quantification, accuracy, precision (intraday and interday), specificity, robustness, and stability, in compliance with International Conference on Harmonization (ICH) guidelines [16].

Linearity: Serial dilutions were prepared from the stock solution of hydrocortisone reference standard $(1 \mathrm{mg} / \mathrm{ml})$ by pipetting $8.0 \mathrm{ml}, 4.0 \mathrm{ml}, 2.0 \mathrm{ml}, 1.6 \mathrm{ml}, 0.8 \mathrm{ml}$, and $0.4 \mathrm{ml}$ of the stock solution into separate $20 \mathrm{ml}$ volumetric flasks. The solutions were made up to volume with the diluent and mixed thoroughly. Solutions prepared were injected and analyzed using the developed method. The linearity of detector response was established by plotting a graph of concentration versus peak area of hydrocortisone standard and determining the correlation coefficient.

Limits of Detection and Quantification: The limit of detection (LOD) and limit of quantification (LOQ) of the new HPLC method were determined from the linear regression curve obtained from the linearity of hydrocortisone. The slope and standard deviations of the responses of the linear curve were used. The formulae for the calculation of the LOD and LOQ are given below: where $\delta$ is standard deviation of the response; is slope of the calibration curve.

Accuracy: Into three separate $10 \mathrm{ml}$ volumetric flasks $1 \mathrm{ml}$ of a $1 \mathrm{mg} / \mathrm{ml}$ standard solution of hydrocortisone was pipetted. $0.8 \mathrm{ml}, 1.0 \mathrm{ml}$, and $1.2 \mathrm{ml}$ of formulated hydrocortisone solution $(0.1 \mathrm{mg} / \mathrm{ml})$ were added to the three volumetric flasks, respectively, to obtain concentrations at $80 \%, 100 \%$, and $120 \%$ levels. The solutions were analyzed using the developed method. Triplicate determinations were made for each solution and mean percentage recovery calculated.

Precision: Both intraday and interday precision of the HPLC method were assessed. For intraday precision, three solutions of different concentrations were prepared in separate 20 mlvolumetric flasks from the stock solution of hydrocortisone reference standard $(1 \mathrm{mg} / \mathrm{ml})$ by pipetting $8.0 \mathrm{ml}, 2.0 \mathrm{ml}$, and $0.4 \mathrm{ml}$ of the stock solution. Solutions were made up to volume with methanol. The various solutions where analyzed thrice during a particular day to obtain chromatograms from which recoveries and relative standard deviations (RSD) were calculated. For interday precision, a one in ten (1 in 10) dilution of the stock standard solution was prepared on three different occasions and analyzed. The solutions were analyzed on three consecutive days using the developed HPLC method to obtain chromatograms and the hydrocortisone content and relative standard deviation (RSD) were determined.

Specificity: The developed HPLC method was investigated for specificity to ensure there was no or minimal interference of analyte of interest from the solvent system. The mobile phase (blank) was analyzed, followed by an injection of a sample solution of hydrocortisone. After a ten-minute wash period, the blank was analyzed again.

Robustness: The robustness of the method was examined by introducing small changes in the composition of the mobile phase. Variation by $\pm 10 \%$ was done with respect to the methanol component of the mobile phase while keeping the composition of the others constant. Chromatograms obtained were analyzed using the RSD of the responses obtained.

Stability: The stability of solutions of hydrocortisone were studied over a period of 8 hours. Triplicate injections were made each hour and the chromatograms recorded.

\section{Assay of Hydrocortisone Preparations}

An amount of finely powdered hydrocortisone powder from each of the nine commercial conventional tablet formulations equivalent to $2.5 \mathrm{mg}$ hydrocortisone was individually weighed accurately and transferred to a $25 \mathrm{ml}$ volumetric flask containing $10 \mathrm{ml}$ of methanol. The solution was sonicated for $5 \mathrm{~min}$ and made up to volume with methanol. The resulting solution was then filtered using Whatman filter paper number 41 . The filtrate obtained was analyzed by making triplicate injections. The controlled-release hydrocortisone tablet and capsule formulations were analyzed in a similar way. In the analysis of the hydrocortisone injections, aliquots equivalent to $2.5 \mathrm{mg}$ hydrocortisone were pipetted from the six (6) injectable preparations into $25 \mathrm{ml}$ volumetric flasks and treated similarly to above. The peak areas of sample were determined, and the amount of hydrocortisone was estimated from the linear regression calibration curves using the developed method. The official United States Pharmacopoeia method [11] was employed in analyzing the commercial samples. Statistical comparison between the official and developed methods was done using Student's -test.

\section{Results and Discussion}

Controlled-release hydrocortisone preparations remain formulations of choice in the therapeutic management of adrenal insufficiency disease. This disease condition is a potentially lifethreatening autoimmune disorder that requires prompt diagnosis and management to avoid fatality. The use of controlled-release 
formulations results in more stable cortisol concentrations during the diurnal cortisol circadian pattern than conventional hydrocortisone products [17]. It is however essential that suitable and accurate analytical methods are made available to assess the quality of the products with regard to their content. The development and validation of a simple isocratic RP-HPLC method for the determination of hydrocortisone in both conventional and controlled-release pharmaceutical formulations were the focus of this study. Review of literature indicates the employment of normal phase stationary support material $[18,19]$ and reverse phase stationary support material [20] for the development of HPLC method and further analyses of hydrocortisone products. There is yet no reported reverse phase HPLC with UV detection method capable of analyzing hydrocortisone in both conventional and controlled-release pharmaceutical formulations. The inclusion of acetic acid as a modifier in the mobile phase system ensured efficient resolution of hydrocortisone with minimal matrix effect from both conventional and controlled-release formulations. Readily available and cost-effective solvents employed in the mobile phase ensured an efficient resolution and separation of hydrocortisone on a reverse phase column. Table 1 presents the optimized chromatographic conditions employed in the determination of hydrocortisone.

Table 1: Optimized chromatographic conditions for the developed HPLC method.

\begin{tabular}{|c|c|}
\hline Parameters & Optimized Conditions \\
\hline Mobile phase & $\begin{array}{r}\text { Methanol/water/acetic acid }(60: 30: 10, \\
\mathrm{v} / \mathrm{v} / \mathrm{v})\end{array}$ \\
\hline HPLC column & JT Baker ODS C18,5m, $4.6 \times 150 \mathrm{~mm}$ \\
\hline Flow rate & $1 \mathrm{ml} / \mathrm{min}$ \\
\hline Wavelength detection & $254 \mathrm{~nm}$ \\
\hline Diluent & Methanol \\
\hline Injection volume & 20 \\
\hline
\end{tabular}

\section{Analytical Method Validation}

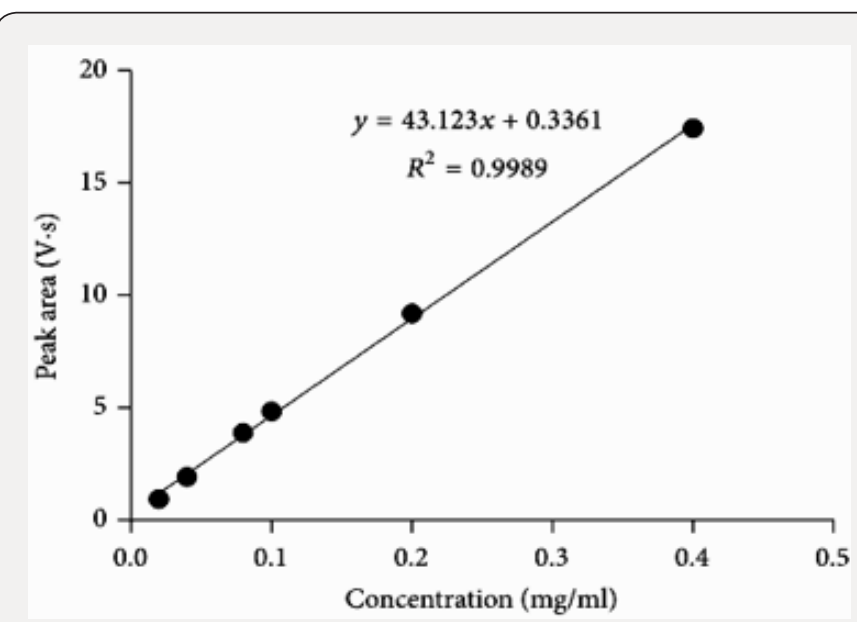

Figure 2: Calibration curve of hydrocortisone showing the linear detectable range $(0.02-0.4 \mathrm{mg} / \mathrm{ml})$.

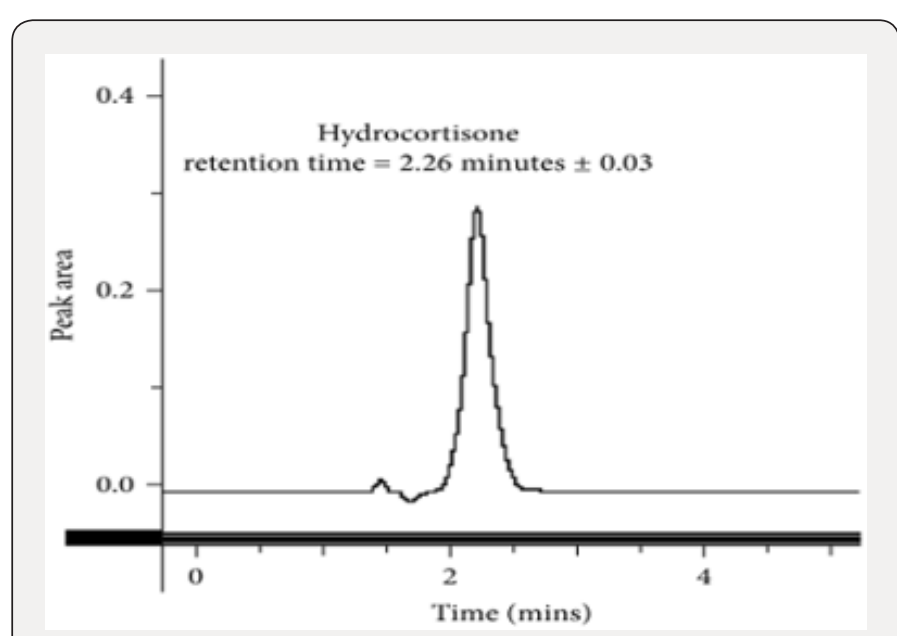

Figure 3: A chromatogram of hydrocortisone standard.

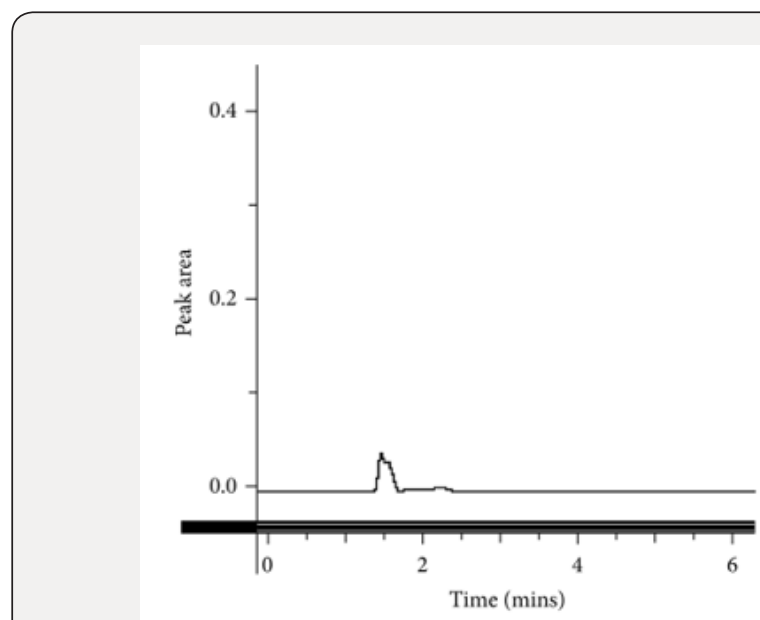

Figure 4: A chromatogram of an excipient in the hydrocortisone tablet.

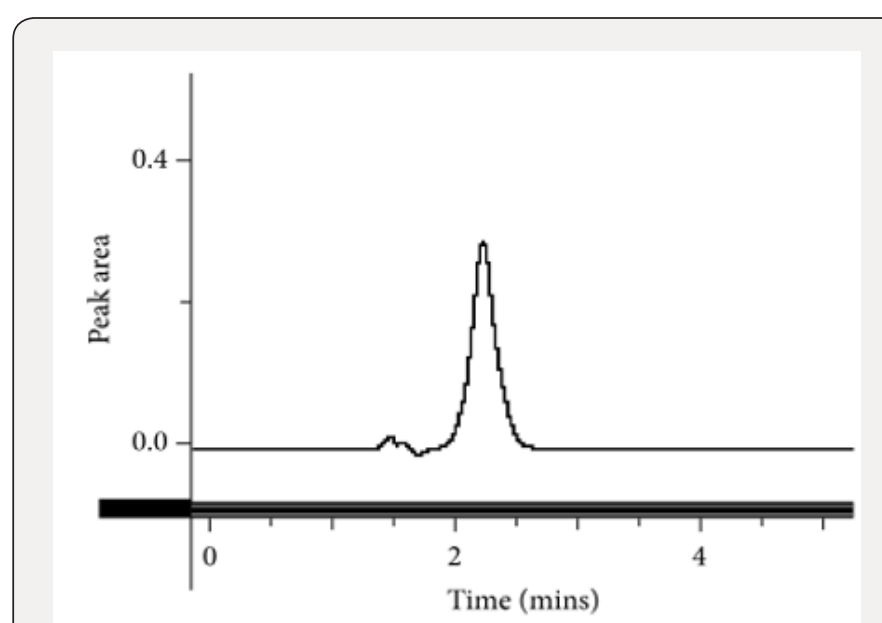

Figure 5: A chromatogram of the hydrocortisone tablet.

This method provides an option for the analyses of hydrocortisone in various salt forms compared to the individual methods available in some official compendia such as the United States Pharmacopoeia [11]. The analytical method being reported 
gave good linear detectable responses in the range of 0.02 to $0.4 \mathrm{mg} / \mathrm{ml}$ with coefficient of correlation of 0.9989 with wellresolved hydrocortisone and excipient peaks (Figures 2-5). The limit of detection and limit of quantification of $1.0662 \times 10^{-2} \mathrm{mg} / \mathrm{ml}$ and $3.23076 \times 10-2 \mathrm{mg} / \mathrm{ml}$, respectively, obtained are an indication of the sensitivity of the method. The method showed good accuracy with good recoveries in the range of 98 to $101 \%$ recorded at three Table 2: Analytical Method Validation.

\begin{tabular}{|c|c|c|c|c|}
\hline Concentration Levels & Amount Taken (Mg/MI) & Amount Added (Mg/Ml) & Amount Recovered & Percentage Recovery (\%) \\
\hline \multirow{3}{*}{$80 \%$} & 0.10 & 0.08 & 0.07820 & 97.75 \\
\cline { 2 - 5 } & 0.10 & 0.08 & 0.07840 & 98.01 \\
\cline { 2 - 5 } & 0.10 & 0.08 & 0.07836 & 97.92 \\
\hline \multirow{3}{*}{$100 \%$} & 0.10 & 0.10 & 0.10073 & 100.73 \\
\cline { 2 - 5 } & 0.10 & 0.10 & 0.10120 & 101.20 \\
\hline \multirow{3}{*}{$120 \%$} & 0.10 & 0.10 & 0.10052 & 9.52 \\
\cline { 2 - 5 } & 0.10 & 0.12 & 0.11998 & 12062 \\
\cline { 2 - 5 } & 0.10 & 0.12 & 0.11934 & \\
\hline
\end{tabular}

Table 3: Intraday precision of proposed HPLC method showing the mean percentage recovery and RSD of hydrocortisone at different concentrations.

\begin{tabular}{|c|c|c|c|c|}
\hline \begin{tabular}{ll|}
$\begin{array}{l}\text { Number of } \\
\text { runs }\end{array}$ & \\
1 & \\
\end{tabular} & $\begin{array}{ll}\begin{array}{l}\text { Concentration } \\
(\mathrm{mg} / \mathrm{ml})\end{array} & \text { levels } \\
0.02 & \end{array}$ & $\begin{array}{l}\text { Amount }(\mathrm{mg} / \mathrm{ml}) \\
0.01990\end{array}$ & $\begin{array}{l}\text { Percentage recovery } \\
(\%) \\
99.52\end{array}$ & $\begin{array}{l}\% \\
\text { RSD } \\
0.55\end{array}$ \\
\hline 2 & \multirow{2}{*}{0.02} & 0.01997 & \begin{tabular}{|l}
99.83 \\
\end{tabular} & \\
\hline 3 & & 0.01975 & 98.76 & \\
\hline 1 & \multirow[t]{3}{*}{0.10} & 0.10052 & 100.52 & \multirow[t]{3}{*}{0.54} \\
\hline 2 & & 0.09945 & 99.45 & \\
\hline 3 & & 0.10000 & 100.03 & \\
\hline 1 & \multirow[t]{3}{*}{0.40} & 0.39952 & 99.88 & \multirow[t]{3}{*}{0.19} \\
\hline 2 & & 0.39828 & 99.57 & \\
\hline 3 & & 0.39964 & 99.91 & \\
\hline
\end{tabular}

Table 4: Inter day precision of proposed HPLC method showing the mean percentage recovery and RSD of hydrocortisone on different days.

\begin{tabular}{|c|c|c|c|}
\hline \multirow{2}{*}{$\begin{array}{c}\text { Number of } \\
\text { Runs }\end{array}$} & \multicolumn{3}{|c|}{ Percentage Recovery (\%) } \\
\cline { 2 - 4 } & Day 1 & Day 2 & Day 3 \\
\hline 1 & 100.52 & 98.52 & 100.16 \\
\hline 2 & 99.45 & 99.67 & 99.51 \\
\hline 3 & 100.03 & 98.36 & 99.72 \\
\hline Mean & 100.00 & 98.85 & 99.80 \\
\hline \% RSD & 0.54 & 0.71 & 0.33 \\
\hline \multicolumn{4}{|c|}{ Mean of three replicate determinations. } \\
\hline
\end{tabular}

Table 5: Results of specificity studies of the proposed HPLC method.

\begin{tabular}{|c|c|}
\hline Parameter & Response \\
\hline Mobile phase & No peak $(-)$ \\
\hline Hydrocortisone & Single peak obtained \\
\hline Mobile phase & No peak $(-)$ \\
\hline \multicolumn{2}{|c|}{$(-)$ : not detected. } \\
\hline
\end{tabular}

concentration levels of $80 \%, 100 \%$, and $120 \%$ (Table 2 ). The method was reproducible with good intraday and interday precision of less than 1\% RSD (Tables 3 \& 4). The new HPLC method showed high specificity and the robustness was less than 1\% RSD (Tables 5 \& 6). The method also demonstrated good stability over a period of $8 \mathrm{~h}$ (<6\% RSD) (Table 7).
Table 6: Robustness of proposed HPLC method showing the mean percentage content of hydrocortisone when conditions were varied.

\begin{tabular}{|c|c|c|}
\hline Sample & Original condition & Varied condition \\
\hline & \% content & \% content \\
\hline 1 & 100.52 & 101.32 \\
\hline 2 & 100.75 & 100.65 \\
\hline 3 & 101.34 & 99.99 \\
\hline Mean & 100.87 & 100.65 \\
\hline \% RSD & 0.42 & 0.67 \\
\hline
\end{tabular}

Table 7: Stability of HPLC method showing the mean recoveries of hydrocortisone in solution over an eight-hour period.

\begin{tabular}{|c|c|c|}
\hline Time (h) & Mean concentration & \% RSD \\
\hline 0 & 100.72 & 0.56 \\
\hline 2 & 100.29 & 0.63 \\
\hline 4 & 98.40 & 1.73 \\
\hline 6 & 95.82 & 3.54 \\
\hline 8 & 93.11 & 5.79 \\
\hline
\end{tabular}




\section{Application of Developed Method to the Analysis of Commercial Samples}

Table 8: characteristics and labelled strength of commercial hydrocortisone preparations analysed using the developed HPLC method (DM) and the USP method.

\begin{tabular}{|c|c|c|c|c|c|c|c|c|}
\hline Code & $\begin{array}{l}\text { Dosage } \\
\text { form }\end{array}$ & Strength & $\begin{array}{l}\text { Country of } \\
\text { manufacture }\end{array}$ & $\begin{array}{l}\text { Batch } \\
\text { number }\end{array}$ & $\begin{array}{c}\text { Date of } \\
\text { manufacture }\end{array}$ & $\begin{array}{l}\text { Expiry } \\
\text { date }\end{array}$ & $\begin{array}{l}\text { Assay" }{ }^{*}(\%) \\
\text { (DM) }\end{array}$ & $\begin{array}{c}\text { Assay }{ }^{*} \\
(\%) \\
\text { (USP) }\end{array}$ \\
\hline HP1 & PFI & $100 \mathrm{mg}$ & Belgium & $14 \mathrm{HB} 24$ & $04 / 2014$ & $03 / 2017$ & 98.41 & 98.60 \\
\hline HP2 & PFI & $100 \mathrm{mg}$ & China & 131255 & $12 / 2013$ & $12 / 2016$ & 102.60 & 102.34 \\
\hline HP3 & PFI & $100 \mathrm{mg}$ & Belgium & $14 \mathrm{HB} 52$ & $12 / 2014$ & $11 / 2017$ & 100.64 & 100.42 \\
\hline HP4 & PFI & $100 \mathrm{mg}$ & India & $5 \mathrm{AB} 01007$ & $10 / 2015$ & $09 / 2018$ & 101.20 & 101.27 \\
\hline HP5 & PFI & $100 \mathrm{mg}$ & Belgium & $15 \mathrm{HB} 22$ & $09 / 2015$ & $08 / 2018$ & 102.80 & 102.83 \\
\hline HP6 & PF1 & $100 \mathrm{mg}$ & India & $5 A E 04010$ & $10 / 2015$ & $09 / 2018$ & 100.63 & 100.35 \\
\hline HT1 & Tablet & $10 \mathrm{mg}$ & China & 150801 & $08 / 2015$ & $08 / 2018$ & 86.80 & 86.45 \\
\hline HT2 & Tablet & $10 \mathrm{mg}$ & France & $5 \mathrm{EH} 3 \mathrm{C}$ & $05 / 2015$ & $05 / 2018$ & 98.90 & 98.94 \\
\hline HT3 & Tablet & $5 \mathrm{mg}$ & France & $5 \mathrm{ET} 4 \mathrm{~B}$ & $04 / 2014$ & $04 / 2017$ & 101.55 & 101.72 \\
\hline HT4 & Tablet & $10 \mathrm{mg}$ & India & KCOO4 & $02 / 2014$ & $02 / 2017$ & 101.27 & 101.65 \\
\hline HT5 & Tablet & $5 \mathrm{mg}$ & India & KD157 & $04 / 2015$ & $04 / 2018$ & 87.69 & 87.36 \\
\hline HT6 & Tablet & $5 \mathrm{mg}$ & India & $\mathrm{KD} 150$ & $04 / 2015$ & $04 / 2018$ & 89.05 & 89.03 \\
\hline
\end{tabular}

Table 9: Characteristics andsss labelled strength of pectin -based modified release hydrocortisone preparations analysed using the developed HPLC method.

\begin{tabular}{lccc} 
Code & Dosage form & Strength & Assay (\%) \\
\hline HM1 & Tablet & $100 \mathrm{mg}$ & 103.36 \\
HM2 & Capsule & $100 \mathrm{mg}$ & 95.99 \\
HM3 & Capsule & $100 \mathrm{mg}$ & 103.29 \\
HM4 & Tablet & $100 \mathrm{mg}$ & 102.41 \\
HM5 & Tablet & $100 \mathrm{mg}$ & 104.38 \\
HM6 & Tablet & $100 \mathrm{mg}$ & 95.34
\end{tabular}

Table 8 presents the characteristics, labelled strength, and assay results of conventional hydrocortisone preparations which were analyzed using both the developed HPLC method and the official USP method. Statistical analysis (-test) of data from the two methods (official/USP and developed) showed no significant difference 0 at a 95\% confidence interval (Table 9). The analytical method developed provides a relatively cheaper alternative technique for routine postmarket analyses of hydrocortisone formulations in resource-poor countries such as Ghana. The validated method was also successfully applied to the analysis of six controlled-release hydrocortisone tablet and capsule formulationsf. The application of the method in the analyses of tablets (conventional and controlledrelease) and parenteral formulations indicated the versatility of the analytical procedure. The analyses of the hydrocortisone formulations yielded percentage hydrocortisone content of 95$104 \%, 96-103 \%$, and $87-103 \%$ for the four controlled-release tablet formulations, two controlled-release capsule formulations, and fifteen conventional hydrocortisone formulations, respectively. All the controlled-release products were of good quality in terms of their content (percentage of content $\geq 90 \%$ ). The percentage of content of hydrocortisone powder was $100.44 \%$. Twelve products (all 6 injections, 6 tablets) out of the 15 commercial hydrocortisone products analyzed were determined to contain the right amounts of hydrocortisone as per United States Pharmacopoeia (USP) method and the developed HPLC method [11]. This study did not cover other pharmacopoeia specifications such as disintegration and dissolution tests.

\section{Conclusion}

It can be concluded that the developed process of hydrocortisone, hydrocortisone sodiumsuccinate 
a) Rearrangement leading from the 11--0H compound to the 11--keto compound via the intermediate halohydrin, is carried out under far more gentle conditions that those described in the European Patent No. 30,368, which presents an advantage both in the level of the reaction yield because the formation of secondary or degradation products is limited,

b) An advantage on the industrial level to the extent that the synthesis is more economical; The blocking in position 3 is remarkably selective in contrast to the known blockings by enol ethers and ketals which lead to mixtures of products blocked in positions 3 and 3,17; The blocking in the 3 --position in the invention is very stable under the reaction conditions used whether they are acidic or basic, and its elimination during synthesis, notably by the action of iodine in a basic medium or iodine in catalytic quantity under gentle oxidizing medium, is very easy; Access to hydrocortisone is possible without going through a hydroxylation stage in the 11--position which is the case with known synthesis using androstenedione at the start. Accordingly, this improves the overall yield of the process.

c) Method for preparation of hydrogenation cortisone sodium succinate reaction temperature is low, fast, easy to produce during the reaction of other impurities, fewer side effects and was concentrated, high yield, where water and other solvents content is low, to lay the foundation for post-drying, hydrogenation of the hydrocortisone sodium succinate prepared in line with CP2005 and USP28 standards, for clinical use

d) Finally concluded that the developed and validated simple, isocratic, sensitive RP-HPLC method is useful for the determination and quantification of hydrocortisone in conventional and controlled-release pharmaceutical formulations. The method was successfully applied to commercial samples which indicate the ability of the analytical method to distinguish between good and poor-quality hydrocortisone products.

\section{Refrences}

1. Diane Clare Rigge, Martin Frederick Jones (2005) Shelf lives of aseptically prepared medicines - stability of hydrocortisone sodium succinate in PVC and non-PVC bags and in polypropylene syringes. Journal of Pharmaceutical and Biomedical Analysis 38(2): 332-336.

2. P Christen, F Kloeti, B Gander (1990) Stability of prednisolone and prednisolone acetate in various vehicles used in semi-solid topical preparations. Journal of Clinical Pharmacy and Therapeutics 15(5): 325-329.
3. Claus Larsen, Peter Kurtzhals, Marianne Johansen (1988) Kinetics of regeneration of metronidazole from hemiesters of maleic acid, succinic acid and glutaric acid in aqueous buffer, human plasma and pig liver homogenate. International Journal of Pharmaceutics 41(1-2): 121-129.

4. Menard Szczebara F (2003) Total biosynthesis of hydrocortisone from a simple carbon source in yeast. Nature Biotechnol 21:143-149.

5. (2016) Hydrocortisone Drugs com American Society of Health System Pharmacists.

6. Becker Kenneth L (2001) Principles and Practice of Endocrinology and Metabolism. Lippincott Williams \& Wilkins pp. 762.

7. Hamilton Richart (2015) Tarascon Pocket Pharmacopoeia 2015 Deluxe Lab Coat Edition. Jones \& Bartlett Learning pp. 202.

8. (2016) Hydrocortisone Pregnancy and Breastfeeding Warnings.

9. Walker SR (2012) Trends and Changes in Drug Research and Development. Springer Science \& Business Media pp. 109.

10. Caldato Milena CF, Fernandes Vânia, T Kater (2004) One-year clinical evaluation of single morning dose prednisolone therapy for 21-hydroxylase deficiency. Arquivos Brasileiros de Endocrinologia e Metabologia 48(5): 705-712.

11. J Elks (2014) The Dictionary of Drugs Chemical Data: Chemical Data, Structures and Bibliographies. Springer pp. 316.

12. Karmas George (1968) J Org Chem 33(6): 2436-2440.

13. Venton (1975) J of Med Chem 18(1): 9-16.

14. J Gregory Reid (1990) Corticoids from 17-oxosteroids. Tetrahedron Letters 31(26): 3669-3672.

15. Aher Nilkanth G (2005) Synthesis of Bile Acid Dimers Linked with 1,2,3-Triazole Ring at C-3, C-11, and C-24 Positions. Synlett 14: 21552158.

16. Breslow Ronald (1980) Biomimtic Control of Chemical Selectivity. Acc Chem Res 13(6): 170-177.

17. Harburn James J (1998) Synthesis of Novel Steroidal Inhibitors of HIV-I Protease. Tetrahedron 54(39): 11907-11924.

18. Peterson DH (1952) Microbiological Transformations of Steroids: I Introduction of Oxygen at Carbon-11 of Progeserone. J Am Chem Soc 74: 5933-5936.

19. Salunke Deepak B (2006) Amino Functionalized Novel Cholic Acid Derivatives Induce HIV-1 Replication and Syncytia Formation in T Cells. J Med Chem 49(8): 2652-2655.

20. Salunke Deepak B (2005) An efficient method for the synthesis of methyl $11 \alpha$-amino- $3 \alpha, 7 \alpha$-diacetoxy-12-oxo-5 $\beta$-cholan-24-oate. Tetrahedron 61(14): 3605-3612.

21. (2015) International Application No. PCT/IN2014/000730, International Search Report and Written Opinion dated, p. 8.

22. Epstein D (2012) The effect of physiological concentrations of bile acids on the in vitro growth of Mycobacterium tuberculosis. South African Medical Journal 102(6): 522-524. 
(C) 9 This work is licensed under Creative

To Submit Your Article Click Here: $\quad$ Submit Article

DOI: 10.32474/LOJMS.2018.01.000121

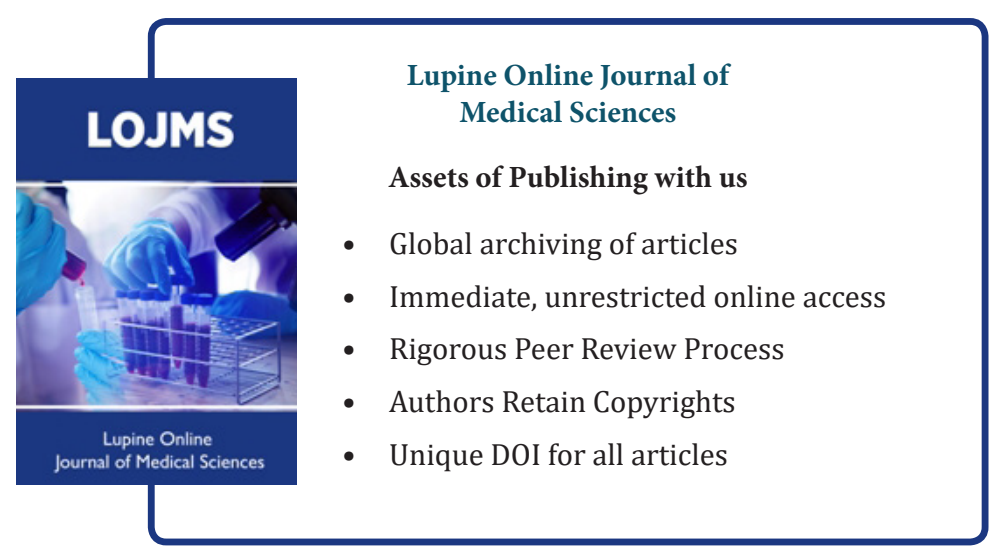

